\title{
CONCENTRAÇÕES SÉRICAS DE TESTOSTERONA EM TOUROS JOVENS GUZERÁ E SUAS ASSOCIAÇÕES COM CARACTERÍSTICAS REPRODUTIVAS
}

\author{
Juliano Cesar Dias ${ }^{1}$, Lucas Luz Emerick², Venício José de Andrade², Jorge André \\ Matias Martins ${ }^{3}$, Vicente Ribeiro do Vale Filho²
}

\author{
1 UFFS \\ 2 UFMG \\ 3 UFC \\ Correspondência: Juliano Cesar Dias: julianocdias@yahoo.com.br
}

\begin{abstract}
RESUMO: O objetivo do presente estudo foi de avaliar o perfil das concentrações séricas de testosterona de bovinos da raça Guzerá, e associá-las com características andrológicas (aspectos físicos e morfológicos do sêmen), circunferência escrotal (CE), classificação andrológica por pontos (CAP), peso corporal e idade. Para este estudo foram avaliados 24 touros com idades de 24 a 34 meses, criados extensivamente. A média na concentração de testosterona foi de $1,36 \mathrm{ng} / \mathrm{mL}$, com influência do horário de coleta nos níveis circulantes, com maior concentração ocorrendo às 7:00 horas e menor ocorrendo às 19:00 horas; observou-se estabilização na concentração de testosterona circulante a partir das 13:00 horas. As correlações observadas entre as concentrações de testosterona e os seguintes parâmetros foram: idade $(0,53 ; p=0,0069)$, peso corporal $(0,72$; $p<0,0001)$, CE $(0,55 ; p=0,0058)$, volume de sêmen $(0,56 ; p=0,0042)$, concentração espermática $(0,71 ; p=0,0003)$, consistência testicular $(0,40 ; p=0,0515)$ e CAP $(0,46 ; p=0,0260)$ sugerindo associação favorável entre as características. Os resultados indicaram compatibilidade entre crescimento corporal e fertilidade com as concentrações séricas de testosterona; e ainda, que os níveis circulantes de testosterona podem auxiliar na identificação e seleção de touros Guzerá com maior potencial reprodutivo.
\end{abstract}

Palavras-chave: andrologia; reprodução; sêmen; zebu

\section{SERUM TESTOSTERONE CONCENTRATIONS IN GUZERAT YOUNG BULLS AND THEIR CORRELATIONS WITH REPRODUCTIVE TRAITS}

\begin{abstract}
Twenty-four Guzerat bulls, raised extensively, from 24 to 34 months of age, were evaluated aiming to determine the bulls serum testosterone concentration profile and associate it with andrological characteristics (physical and morphological aspects), scrotal circumference (SC), Breeding Soundness Evaluation for Zebu (BSEz), body weight and age. The average of testosterone concentration was $1.36 \mathrm{ng} / \mathrm{mL}$, with influence of time of collection on circulating levels, with the higher concentration occurring at 7:00 am and the lowest at 7:00 pm. The phenotypic correlations observed between testosterone and age $(0.53 ; p=0.0069)$, body weight $(0.72 ; p<0.0001)$, $S C(0.55 ; p=0.0058)$, semen volume $(0.56 ; p=0.0042)$, sperm concentration $(0.71 ; p=0.0003)$, testicle consistence $(0.40$; $\mathrm{p}=0.0515)$ and BSEz $(0.46 ; p=0.0260)$ suggest favorable associations among those characteristics. The results indicate compatibility between body growth and fertility with serum testosterone concentrations; and also indicate that circulating levels of testosterone may help on identification and selection of Guzerat bulls with major reproductive potential.
\end{abstract}

Key Words: andrology; reproduction; semen; zebu 


\section{INTRODUÇÃO}

A seleção andrológica envolve um grande universo de características a serem analisadas e selecionadas, que vão desde os aspectos mais básicos, mas também fundamentais, como o exame clínico e da biometria testicular, passando também pela avaliação dos aspectos físicos e morfológicos do sêmen, classificação andrológica por pontos, chegando até mesmos aos parâmetros de avaliações funcionais e bioquímicas, ligados à capacidade de fecundação espermática.

A utilização de reprodutores selecionados por avaliação andrológica tem como finalidade a melhora na eficiência reprodutiva do rebanho visando aumentar a lucratividade do sistema, prática ainda incipiente na maioria dos rebanhos comerciais. O aumento da lucratividade pela diminuição da duração do ciclo produtivo, da permanência e a amortização dos custos de mantença do animal na fazenda dependem essencialmente da precocidade sexual média do rebanho. A identificação de touros sexualmente maduros em idades mais precoces, que transmitam esta característica para sua progênie, acarreta grande impacto econômico no sistema produtivo (Silveira et al., 2010).

Neste contexto, a caracterização biológica dos diferentes genótipos ou grupamentos genéticos de bovinos disponíveis no Brasil é fundamental para a proposição de alternativas adequadas de manejo, visando o aumento da eficiência reprodutiva. Assim, a busca de indicadores biológicos correlacionados com parâmetros de importância econômica se faz necessário (Barbosa et al., 1992).

O estudo de níveis de testosterona no zebuíno tem sido pouco enfatizado, entretanto, Post et al. (1987) descreveram que avaliações da testosterona circulante possam ser indicadores úteis para a fertilidade de um rebanho de tal modo que, a resposta da testosterona em touros jovens seja um preditor efetivo da fertilidade, além de estar relacionada com a idade à puberdade em tourinhos.

A testosterona é essencial à função reprodutiva dos machos, pois atua estimulando os estádios finais da espermatogênese, prolonga a vida útil dos espermatozoides no epidídimo e estimula 0 crescimento, 0 desenvolvimento e a atividade secretora dos órgãos sexuais do macho, bem como, as características sexuais secundárias; o comportamento sexual ou a libido do macho também são controladas pelos andrógenos (Hafez, 1995).

O presente estudo objetivou avaliar as concentrações séricas de testosterona em touros jovens da raça Guzerá, e suas associações com parâmetros andrológicos, circunferência escrotal, classificação andrológica por pontos e peso corporal.

\section{MATERIAL E MÉTODOS}

O trabalho foi desenvolvido na Fazenda Palestina, município de Unaí, noroeste do estado de Minas Gerais, tendo como coordenadas geográficas $16^{\circ} 35^{\prime} \mathrm{S}$ de latitude e $46^{\circ} 47^{\prime} \mathrm{W}$ de longitude, situada em área de Cerrado.

Foram avaliados quanto aos aspectos clínico-andrológicos: circunferência escrotal (CE) e aspectos físicos e morfológicos do sêmen, segundo critérios do Colégio Brasileiro de Reprodução Animal (1998), 24 touros da raça Guzerá, com idades variando de 24 a 34 meses. Sendo os animais submetidos à classificação andrológica por pontos (CAP), de acordo com Vale Filho (1989).

O sistema de manejo é extensivo, e o rebanho é mantido em regime de pastejo (Brachiaria decumbens, Brachiaria brizantha e Panicum 
maximum), com suplementação volumosa a base de silagem de milho, e concentrado protéico ( $22 \%$ de proteína bruta) no período seco, e suplementação mineral ad libitum o ano todo.

As medições de circunferência escrotal (CE) foram obtidas por meio de fita métrica posicionada na região de maior diâmetro da bolsa escrotal. Quanto ao sêmen foram avaliados os aspectos físicos (volume seminal, motilidade, vigor e concentração espermáticos) e morfológicos, classificados em defeitos maiores (DM), menores (Dm) e totais (DT).

As colheitas de sêmen $(n=24)$ foram realizadas com auxílio de aparelho de eletroejaculação, dois dias antes da coleta de sangue, $e$ as avaliações físicas do sêmen realizadas imediatamente após as colheitas. Para a avaliação morfológica, o sêmen foi fixado em solução de formol salina e transportado em temperatura ambiente até os laboratórios de andrologia da Escola de Veterinária da Universidade Federal de Minas Gerais.

Para avaliação das concentrações séricas de testosterona, os animais foram submetidos a coletas de sangue ( $n=168)$, por punção da veia jugular, utilizando-se o sistema de coleta a vácuo, em tubos de vidro de cinco mililitros, sem anticoagulante. As coletas de sangue foram realizadas a cada duas horas, por um período de 12 horas (07:00, 09:00, 11:00, 13:00, 15:00, 17:00 e 19:00 horas).

Para a coleta de sangue, os animais foram divididos em dois grupos, com 12 animais cada, sendo as coletas iniciadas sempre pelo mesmo grupo, para que os intervalos de coleta se mantivessem dentro de uma mesma faixa de tempo.

Imediatamente após a coleta, a amostra de sangue era colocada em banho-maria a $\quad 4^{\circ} \mathrm{C}$ por aproximadamente, 30 minutos, sendo posteriormente centrifugada a $300 \mathrm{~g}$ por 20 minutos. O soro sanguíneo, obtido após a centrifugação, era transferido para tubos criogênicos esterilizados, devidamente identificados, e colocados sob refrigeração a $-20^{\circ} \mathrm{C}$ (Valle e Dode, 1991), para posterior armazenamento em nitrogênio líquido $\left(-196^{\circ} \mathrm{C}\right)$, até o momento da análise.

A dosagem quantitativa das concentrações séricas de testosterona foi realizada em radioimunoensaio de fase sólida pelo método direto, cujo princípio baseia-se na competição entre antígenos dos padrões e das amostras com quantidade constante de antígeno marcado como traçador $\left({ }^{125} \mathrm{I}\right)$, para os sítios de ligação específicos dos anticorpos. A quantidade de antígeno não radioativo (testosterona) da amostra a se dosar, é inversamente proporcional à quantidade de antígeno marcado. $O$ complexo antígeno anticorpo é precipitado para separar a forma ligada da forma livre, procedendo posteriormente à contagem em contador gama; com determinação de uma curva padrão e a obtenção dos resultados expressos em nanogramas por mililitro de soro sanguíneo.

As análises das concentrações séricas de testosterona foram realizadas no Laboratório de Endocrinologia e Metabolismo do Instituto de Ciências Biológicas da Universidade Federal de Minas Gerais, utilizando-se kits de testosterona total COAT-A-COUNT ${ }^{\circledR}$ (Diagnostic Products Corporation, Los Angeles, Califórnia, USA).

Para análise dos dados, referentes aos níveis de testosterona, procedeu-se a transformação logarítmica utilizando $Y$ $=\log (X+1)$, devido ao alto coeficiente de variação observado (Sampaio, 2002).

Para observação do efeito do horário da coleta sobre as concentrações séricas de testosterona, fez-se comparação de médias usando- 
se 0 teste de Student-Neuman-Keuls (SNK), com 5\% de probabilidade (Sampaio, 2002). Buscaram-se também associações, através de correlações de Pearson (dados paramétricos) e Spearman (dados não paramétricos), entre os níveis séricos de testosterona e idade, peso corporal, circunferência escrotal, características físicas e morfológicas do sêmen, consistência testicular e classificação andrológica por pontos, com recursos do SAS (1996).

\section{RESULTADOS E DISCUSSÃO}

$\mathrm{Na}$ Tabela 1 são apresentadas as médias de idade, peso corporal, circunferência escrotal, características seminais e CAP de touros jovens da raça Guzerá. Os dados são semelhantes aos descritos na literatura para touros Guzerá, na mesma faixa etária (Pinto et al., 1989; Torres-Júnior e Henry, 2005), se encontrando dentro do padrão descrito para touros zebuínos (Vale Filho, 1989).

\section{Tabela 1 - Médias e desvios-padrão da idade, peso corporal, características físicas e morfológicas do semmen e classificação andrológica por pontos (CAP) de touros jovens Guzerá \\ Idade Peso CE Mot. Vigor DM Dm DT Vol. Conc. CAP \begin{tabular}{ccccccccccc} 
(meses) & $(\mathrm{Kg})$ & $(\mathrm{cm})$ & $(\%)$ & $(0-5)$ & $(\%)$ & $(\%)$ & $(\%)$ & $(\mathrm{ml})$ & $\left(\mathrm{x} 10^{6} \mathrm{sptz} / \mathrm{ml}\right)$ & $(0-100)$ \\
\hline 29,4 & 464,1 & 32,3 & 60,2 & 4,2 & 7,5 & 12,1 & 19,6 & 9,1 & 284,5 & 70,7
\end{tabular} \begin{tabular}{ccccccccccc} 
\pm & \pm & \pm & \pm & \pm & \pm & \pm & \pm & \pm & \pm & \pm \\
3,2 & 99,5 & 2,7 & 7,3 & 0,7 & 4,2 & 5,5 & 6,4 & 1,5 & 147,1 & 15,1 \\
\hline
\end{tabular} Peso = peso corporal; CE = circunferência escrotal; Mbt. = motilidade espermátics; Vigo = vigó

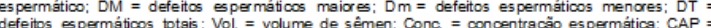

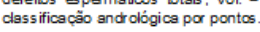

As amplitudes de variações das secreções de testosterona no soro sanguíneo de touros jovens Guzerá durante o período de coleta, oscilaram desde níveis inferiores a $0,02 \mathrm{ng} / \mathrm{mL}$ até $12,84 \mathrm{ng} / \mathrm{mL}$. Estes valores são inferiores aos descritos por Barbosa (1987), e com limites de variação mais amplos que os descritos por Santos (1996), ambos em touros Nelore aos 27 e 24 meses de idade, respectivamente, mostrando a variabilidade deste hormônio em machos zebuínos.

A média encontrada na concentração sérica de testosterona foi de 1,36 ng/mL (Tabela 2), valor superior aos encontrados por Barbosa (1987) para touros Canchim aos 27 meses de idade $(1,2 \mathrm{ng} / \mathrm{mL})$ e Santos (1996) para touros Nelore aos 24 meses de idade $(1,24 \mathrm{ng} / \mathrm{mL})$; porém inferiores as encontradas por Barbosa (1987) para touros Nelore aos 27 meses de idade (3,1 ng/mL), Aguiar et al. (2006) para touros Angus com 38 semanas de idade e Coser et al. (1981) em touros zebus (2,52 ng/mL), com predominância de animais da raça Gir.

Tabela 2 - Médias e desvios-padrão de concentrações séricas de testosterona em touros Guzerá em diferentes horários dé coleta

\begin{tabular}{cccccccc}
\hline \multicolumn{7}{c}{ Horários de coleta $(\mathbf{n g} / \mathbf{m L})$} & \multirow{2}{*}{ G eral } \\
\cline { 1 - 6 } $\mathbf{7 h}$ & $\mathbf{9 h}$ & $\mathbf{1 1 h}$ & $\mathbf{1 3 h}$ & $\mathbf{1 5 h}$ & $\mathbf{1 7 h}$ & $\mathbf{1 9 h}$ & \\
\cline { 1 - 5 } 4,42 & 2,29 & 1,00 & 0,55 & 0,41 & 0,44 & 0,36 & 1,36 \\
\pm & \pm & \pm & \pm & \pm & \pm & \pm & \pm \\
$3,65^{\mathrm{a}}$ & $2,99^{\circ}$ & $1,12^{\circ}$ & $0,57^{\infty}$ & $0,43^{\circ}$ & $0,69^{\circ}$ & $0,33^{\circ}$ & 1,12 \\
\hline
\end{tabular}

Observaram-se

diferenças

$(p<0,05)$ entre horários de coleta, com concentração máxima de testosterona nos níveis séricos, às sete horas $(4,42$ $\mathrm{ng} / \mathrm{mL})$ e mínima às 19 horas $(0,36$ $\mathrm{ng} / \mathrm{mL}$ ), com estabilização na concentração sérica basal ocorrendo a partir das 13 horas $(0,55 \mathrm{ng} / \mathrm{mL})$ (Tabela 2 e Figura 1).

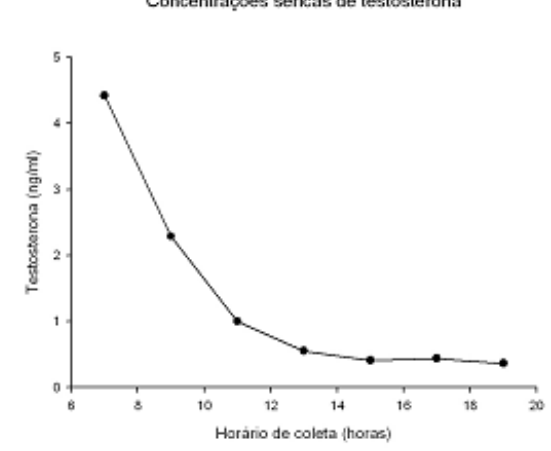

Figura 1 - Concentrações séricas médias de testosterona em touros da raça Guzerá, em diferentes horários de coleta.

Verificou-se diminuição nos níveis séricos de testosterona no transcorrer do dia, similar ao relatado por Aranguren-Méndez et al. (1995); sugerindo influência do período do dia na concentração periférica desse hormônio.

Apesar de terem sido observadas variações nas concentrações de testosterona, observou-se apenas um pico hormonal às sete horas, 
semelhante ao observado por Santos et al. (2000), que observou em touros Nelore, um pico às nove horas.

Sanwal et al. (1974), trabalhando com touros da raça Norueguês Vermelho descreveram a ocorrência de três picos de testosterona (6:00, 12:00 e 22:00 horas); já Barbosa (1987) descreveu uma tendência de ocorrência de picos de testosterona a cada seis horas em touros Canchim, e a cada oito horas em touros Nelore, quando avaliados por um período de 24 horas. A metodologia e os horários de coleta, utilizados no presente estudo, permitiram estabelecer apenas um pico (Figura 1), podendo-se especular que em touros jovens Guzerá estes picos devam ocorrer a intervalos maiores.

Constatou-se

correlação favorável $(0,53 ; p=0,0069)$ entre a idade e os níveis de testosterona nos tourinhos Guzerá (Tabela 3). Devkota et al. (2008) citam baixa correlação entre a idade $e$ as concentrações de testosterona em touros Holandês, na puberdade e pós-puberdade, 0,23 e 0,13 , respectivamente.

\begin{tabular}{|c|c|}
\hline & Testosterona (ng/mL) \\
\hline Idade (meses) & $0,53(0,0069)^{*}$ \\
\hline Peso corporal (Kg) & $0,72(<0,0001)$ \\
\hline Circunferência escrotal (cm) & $0,55(0,0038)$ \\
\hline Motilid ade espermática (\%) & $0,32(0,1283)$ \\
\hline Volume semin al (ml) & $0,56(0,0042)$ \\
\hline Concentração espermática $\left(\times 10^{5} \mathrm{sptz} / \mathrm{ml}\right)$ & $0,71(0,0003)$ \\
\hline Defeitos espermáticos maiores (\%) & $-0,32(0,1251)$ \\
\hline Defeitos espermáticos menores $(\%)$ & $-0,10(0,6323)$ \\
\hline Total de defeitos espermáticos $(\%)$ & $-0,30(0,1542)$ \\
\hline Consistência testicular (0-5) & $0,40(0,0515)$ \\
\hline Vigor espermático $(\%)$ & $0,30(0,1433)$ \\
\hline Turbilhonamento (0-5) & $0,24(0,2324)$ \\
\hline Classificação and rológica por pontos $(0-100)$ & $0,46(0,0260)$ \\
\hline
\end{tabular}

Renaville et al. (1983) e Moura e Ericksson (1997) sugeriram que o aparecimento precoce do perfil pulsátil da testosterona poderia ser indicativo do desenvolvimento testicular, do início da puberdade e da maturidade sexual dos machos; podendo, desta forma, selecionar precocemente os animais que entrarão na reprodução.

A associação entre a concentração sérica de testosterona e peso corporal $(0,72 ; p<0,0001)$ foi verificada pela correlação simples entre as características. Devkota et al. (2008) encontraram correlações de 0,21 e 0,20, entre o peso corporal e a testosterona em touros Holandês, na puberdade e pós-puberdade, respectivamente.

A associação de peso corporal e testosterona pode ser explicada pelos efeitos anabólicos deste hormônio, onde se destacam: o aumento da massa muscular, da concentração da hemoglobina, do hematócrito, da retenção de nitrogênio, da deposição de cálcio nos ossos e diminuição das reservas de gordura do corpo. Dentre os mecanismos anabólicos desencadeados para aumento da massa muscular, incluem-se: aumento da síntese protéica via RNA mensageiro, balanço nitrogenado positivo, inibição dos efeitos catabólicos na massa muscular esquelética, estimulação da formação de osso, inibição do catabolismo protéico e estímulo da eritropoiese. Os efeitos anabólicos ocasionam retenção de nitrogênio, um constituinte básico da proteína, promovendo assim crescimento e desenvolvimento de massa muscular através da uma melhor utilização da proteína ingerida (Lise et al., 1999).

Outra forma de especular a associação entre a melhor condição corporal e as concentrações de testosterona, pode ser encontrada nos resultados de Brito et al. (2007) que observaram que a melhoria na nutrição dos animais resultou em aumento nas concentrações de testosterona, que foi associado com uma maior concentração de fator de crescimento semelhante à insulina - I (IGF - I), considerado importante mediador da ação metabólica e de estímulo ao 
crescimento,

correlacionando-se positivamente à taxa de ganho de peso vivo e à eficiência alimentar (Cervieri et al., 2005).

A associação entre a concentração de testosterona e a CE, em touros jovens da raça Guzerá, se apresentou favorável $(0,55 ; p=0,0038)$. Lunstra et al. (1978) encontraram valor semelhante em touros Hereford de sete a 13 meses de idade. Os autores descrevem ainda correlações entre 0,09 e 0,47 para touros de outras raças taurinas e seus cruzamentos. AragurenMéndez et al. (1995) encontraram correlação de 0,47 em tourinhos púberes 5/8 Holandês e 5/8 Pardo Suíço, o que confirma a andrógenodependência da CE.

Verificou-se também correlação favorável e de alta magnitude entre a concentração espermática e a concentração sérica de testosterona $(0,71 ; p=0,0003)$ nos animais avaliados.

A elevação nos níveis basais de testosterona é consequência da diferenciação das células de Leydig e está associada à proliferação das células germinativas, eventos essenciais para a puberdade (Amann e Schanbacher, 1983). O processo de multiplicação, meiose e diferenciação das células germinativas em estádios mais avançados de desenvolvimento está sincronizado com as mudanças morfológicas e a expressão gênica nas células de Sertoli e Leydig e as secreções hormonais.

As gonadotrofinas (FSH e $\mathrm{LH}$ ) controlam a proliferação e diferenciação das células de Sertoli e Leydig desde a fase pós-natal, de modo que os esteroides e fatores de crescimento secretados por estas células têm ação direta ou indireta sobre 0 desenvolvimento das células germinativas (Anway et al., 2003; Walker, 2003; Aguiar et al., 2006).

A ação direta e indireta da testosterona na multiplicação e diferenciação das células germinativas, que irão originar os espermatozoides durante o processo da gametogênese, pode ser a explicação da associação deste hormônio com a concentração espermática nos touros já maturos sexualmente.

Observou-se associação favorável entre volume seminal e concentração de testosterona $(0,56$; $\mathrm{p}=0,0042)$, em touros Guzerá. Estes dados podem ser explicados em parte pela associação encontrada entre a testosterona e a produção espermática, através da maior concentração de espermatozoides no ejaculado, e ainda pela ação direta da testosterona nas glândulas sexuais acessórias, com aumento no tamanho e função (González, 2002); sendo estas glândulas responsáveis pela maior fração do ejaculado.

Constatou-se ainda, correlação favorável entre os níveis séricos de testosterona e a consistência testicular $(0,40 ; \quad p=0,0515)$, sugerindo que maiores concentrações circulantes de testosterona levariam ao aumento na tensão superficial dos testículos. Vale Filho (1997), descrevendo a avaliação genital de touros, citou a consistência testicular como parâmetro auxiliar na identificação de produção espermática normal.

Desta forma, os resultados encontrados neste trabalho indicam que maiores níveis sanguíneos de testosterona, estão associados, indiretamente, ao processo normal de gametogênese; fato reforçado pelas associações favoráveis deste hormônio com a concentração espermática, semelhantemente aos resultados de Araguren-Méndez et al. (1995) que descrevem a andrógeno-dependência de alguns eventos em tourinhos mestiços.

A associação favorável entre o índice de classificação andrológica (CAP) e os níveis periféricos de 
testosterona em touros Guzerá $(0,46$; $\mathrm{p}=0,0260)$, pode ser explicada pelo fato da CE ser responsável por até $40 \%$ na pontuação máxima dos animais submetidos a este índice; tendo a CE alta associação com a testosterona neste estudo (Tabela 3 ).

Não foram encontrados na literatura, dados referentes às associações entre concentrações de testosterona e consistência testicular e CAP, sobretudo em touros da raça Guzerá.

Não se registraram correlações $(p>0,05)$ entre os níveis circulantes de testosterona e motilidade, vigor, turbilhonamento e defeitos espermáticos (maiores, menores e totais), confirmando os achados de literatura (Barbosa, 1987; Devkota et al., 2008).

Abdel Malak e Thibier (1985) concluíram que assim que os processos fisiológicos da espermatogênese são iniciados e controlados pelas secreções hormonais, as variações qualitativas e quantitativas do sêmen são independentes das flutuações espontâneas da testosterona, o que concorda parcialmente com os dados encontrados neste estudo.

\section{CONCLUSÃO}

Os níveis circulantes de testosterona em touros Guzerá sofrem variações, mantendo níveis basais com o transcorrer do dia. Em touros jovens Guzerá, a concentração sérica de testosterona se apresenta associada a características indicativas de melhor desempenho e fertilidade; com correlações favoráveis entre a testosterona e o peso corporal, a circunferência escrotal, a concentração espermática e o volume do sêmen. A testosterona pode ser um parâmetro auxiliar na identificação e seleção de touros jovens da raça Guzerá, com maior potencial reprodutivo.

\section{REFERÊNCIAS}

ABDEL MALAK, G.; THIBIER, M. Lack of between spontaneous fluctuations of $\mathrm{FSH}, \mathrm{LH}$ and testosterone and semen output quality in young postpubertal bulls. Zuchthygiene, v.20, n.5, p.222-228, 1985.

AGUIAR, G.V.; ARAÚJO,A.A.; MOURA, A.A.A. Desenvolvimento testicular, espermatogênese e concentrações hormonais em touros Angus. Rev Bras de Zootec, v.35, n.4, p.1629-1638, 2006.

AMANN, R.P.; SCHANBACHER, B.D. Physiology of male reproduction. Journal of Animal Science, v.57, suppl., p.380-403, 1983.

ANWAY, M.D.; LI, Y.; RAVINDRANATH, N. et al. Expression of testicular germ cell genes identified by differential display analysis. Journal of Andrology, v.24, n.2, p.173-184, 2003.

ARAGUREN-MÉNDEZ, J.; MADRID-BURY, N.; GONZÁLEZ-STAGNARO, C. et al. Pubertad em toretes $5 / 8$ Holstein y 5/8 Pardo suizo. Revista de la Facultad de Agronomía (LUZ), v.12, p.393-407, 1995.

BARBOSA, R.T. Comportamento sexual, biometria testicular, aspectos do sêmen e níveis plasmáticos de testosterona, em touros Canchim e Nelore. 1987. 135p. Dissertação (Mestrado em Medicina Veterinária) - Escola de Veterinária, UFMG, Belo Horizonte.

BARBOSA, RT; FONSECA, V.O.; BARBOSA, P.F. et al. Concentrações plasmáticas de testosterona e suas relações com características reprodutivas em touros das raças Canchim e Nelore. Revista Brasileira de Reprodução Animal, v.16, n.1-2, p.1-11, 1992.

BRITO, L.F.C.; BARTH, A.D.; RAWLINGS, N.C. et al. Effect of improved nutrition during calfhood on serum metabolic hormones, gonadotropins, and testosterone concentrations, and on testicular development in bulls.

Domestic Animal Endocrinology, v.33, n.4, p.460-469, 2007.

CERVIERI, R.C.; ARRIGONI, M.B.;

CHARDULO, L.A.L. et al. Peso vivo final, ganho de peso, características de carcaça e concentrações plasmáticas de IGF-I e hormônios tireoideanos de bezerros mestiços Angus-Nelore recebendo somatotropina bovina recombinante (rbST) até a desmama. Rev Bras de Zootec, v.34, n.6, p.2009-2019, 2005.

COLÉGIO BRASILEIRO DE REPRODUÇÃO ANIMAL. Manual para exame andrológico e 
avaliação de sêmen animal. 2.ed. Belo Horizonte: CBRA, 1998. 49p.

COSER, A.M.L.; FONSECA, V.O.; CHOW, L.A. Níveis de testosterona plasmática em touros zebus (Bos indicus) submetidos à degeneração testicular experimental. Arquivos da Escola de Vet da UFMG, v.33, n.2, p.299-304, 1981.

DEVKOTA, B.; KOSEKI, T.; MATSUI, M. et al. Relationships among age, body weight, scrotal circumference, semen quality and peripheral testosterone and estradiol concentrations in pubertal and postpubertal Holstein bulls. $\mathbf{J}$ of Vet Medical Science, v.70,n.1 p.119-121, 2008.

GONZÁLEZ, F.H.D. Introdução à endocrinologia reprodutiva veterinária. Porto Alegre: UFRGS, 2002. 87p. Disponível em: http://www.ufrb.edu.br/nera/artigoscientificos/13-introducao-a-endocrinologiareprodutiva-veterinaria/download. Acesso em: 09/01/2014.

HAFEZ, E.S.E. Reprodução animal. 6.ed. São Paulo: Manole Ltda., 1995. 582p.

LISE, M.L.Z.; GAMA E SILVA, T.S.; FERIGOLO, $M$. et al. O abuso de esteroides anabólicoandrogênicos em atletismo. Revista da Associação Médica Brasileira, v.45, n.4, p.364-370, 1999.

LUNSTRA, D.D.; FORD, J.J; ECHTERNKAMP, S.E. Puberty in beef bulls: hormone concentrations, growth, testicular development, sperm production and sexual aggressiveness in bulls of different breeds. Journal of Animal Science, v.46, n.4, p.1054-1062, 1978.

MOURA, A.A.; ERICKSSON, B.H. Age-related changes in peripheral hormone concentrations and their relationship with testis size and number of Sertoli and germ cells in yearling beef bulls. $\mathbf{J}$ of Repr and Fertility, v.111, p.183-190, 1997.

PINTO, P.A.; SILVA, P.R.; ALBUQUERQUE, L.G. et al. Avaliação da biometria testicular e capacidade de monta em bovinos das raças Guzerá e Nelore. Rev Bras de Reprodução Animal, v.13, n.3, p.151-156, 1989.

POST, T.B.; CHRISTENSEN, H.R.; SEIFERT, G.W. Reproductive performance and productive traits of beef bulls selected for different levels of testosterone response to $\mathrm{GnRH}$.

Theriogenology, v.27, p.317-328, 1987.

RENAVILLE, R.; FABRY, J.; HALLEUX, V. et al. Testosterone plasma profile, as a function of age in young bulls from the bovine double-muscled Belgian white blue breed a preliminar report. Theriogenology, v.19, p.159-167, 1983.
SAMPAIO, I.B.M. Estatística aplicada à experimentação animal. 2.ed. Belo Horizonte: FEP-MVZ, 2002. 265p.

SANTOS, M.D. Perfil de testosterona e metabólitos lipídicos, circunferência escrotal e aspectos do sêmen de touros zebu alimentados com dois níveis de concentrado e lipídeos. 1996. 64p. Dissertação (Mestrado em Zootecnia) - Faculdade de Zootecnia, Universidade Federal de Viçosa, Viçosa.

SANTOS, M.D.; TORRES, C.A.A.; RUAS, J.R.M. et al. Concentração sérica e efeito circadiano da testosterona em touros da raça Nelore. In: REUNIÃO DA SOCIEDADE BRASILEIRA DE ZOOTECNIA, 37, 2000, Viçosa. Anais... Viçosa: SBZ, 2000. CD-ROM.

SANWAL, P.C.; SUNDBY, A.; EDQVIST, L.E. Diurnal variation of peripheral plasma levels of testosterone in bulls measured by a rapid radioimmunoassay procedure. Acta Veterinaria Scandinavica, v.15, p.90-99, 1974.

SAS. User's Guide. SAS Inst., Inc., Cary, NC, 1996.

SILVEIRA, T.S.; SIQUEIRA, J.B.; GUIMARÃES, S.E.F. et al. Maturação sexual e parâmetros reprodutivos em touros da raça Nelore criados em sistema extensivo. Revista Brasileira de Zootecnia, v.39, n.3, p.503-511, 2010.

TORRES-JÚNIOR, J.R.S.; HENRY, M. Sexual development of Guzerat (Bos taurus indicus) bulls raised in a tropical region. Animal Reproduction, v.2, n.2, p.114-121, 2005.

VALE FILHO, V.R. Padrões de sêmen bovino, para o Brasil. Análise e sugestões. In: CONGRESSO BRASILEIRO DE REPRODUÇÃO ANIMAL, 8, 1989, Belo Horizonte. Anais... Belo Horizonte: CBRA, p.94118, 1989.

VALE FILHO, V.R. Andrologia no touro: avaliação genital, exame do sêmen e classificação por pontos. Revista Brasileira de Reprodução Animal, v.21, n.3, p.7-13, 1997.

VALLE, E.R.; DODE, M.A.N. Efeito do tempo e da temperatura, entre a coleta e a centrifugação, na concentração de progesterona do soro e plasma de vacas Nelore. Pesquisa Agropecuária Bras, v.26, n.4, p.479-485, 1991.

WALKER, W.H. Molecular mechanisms controlling Sertoli cell proliferation and differentiation. Endocrinology, v.144, n.9, p.3719-3721, 2003. 